\title{
Travelers' Reported Preventive Health Behavior in Jinja, Uganda
}

\author{
Travis Bias ${ }^{1,2 *}$, Carl Allen ${ }^{3}$, Anna Buckley ${ }^{4}$, Alex Hillman $^{5}$, Tamsin Lillie ${ }^{6}$, Immaculate Goima $^{7}$, \\ Gissela Nyakunga ${ }^{8}$, Melanie Willimann ${ }^{9}$, Christopher Sanford ${ }^{10}$
}

${ }^{1}$ London School of Hygiene and Tropical Medicine, London, UK

${ }^{2}$ Department of Internal Medicine, Busitema University Faculty of Health Sciences, Mbale, Uganda

${ }^{3}$ Miranda Medical Centre, Sydney, Australia

${ }^{4}$ Consultant in Emergency Medicine, University College London Hospital, London, UK

${ }^{5}$ York Hospital, York Teaching hospital NHS Foundation Trust, York, UK

${ }^{6}$ Paediatric Department, Rotorua Hospital, Rotorua, New Zealand

${ }^{7}$ Muhimbili National Hospital, Dar Es Salaam, Tanzania

${ }^{8}$ Department of Internal Medicine, Kilimanjaro Christian Medical Centre, Moshi, Tanzania

${ }^{9}$ Pediatric Emergency Medicine, Alberta Children's Hospital, University of Calgary, Calgary, Alberta, USA

${ }^{10}$ Department of Family Medicine and Global Health, University of Washington, Seattle, WA, USA

Corresponding Author: Travis Bias, DO, MPH, DTM\&H; London School of Hygiene and Tropical Medicine, Keppel

Street, London WC1E 7HT, UK. Email: TravisGaujotBias@gmail.com

Received August 2, 2016; Accepted September 28, 2016; Online Published December 5, 2016

\begin{abstract}
Introduction: Increasing international travel to low-income areas is confronting travelers with new health threats. This study investigated international travelers' health advice, behavior, and information needs in a low-income setting.

Methods: This is a descriptive and cross-sectional study. Between October 27-31, 2014, 127 semi-structured surveys were conducted in Jinja, Uganda with international travelers selected by central-location intercept convenience sampling. Data was analyzed using SPSS software.

Results: Among all the 127 respondents, 88\% sought pre-travel medical advice. The surveys revealed a pool of many traveling longer than six months (32.3\%) with $72.3 \%$ of those being for volunteer purposes, while $41.2 \%$ of those traveling for less than one month (40.2\%) were volunteers. Compliance with malaria chemoprophylaxis was reported by $94.1 \%$ of those traveling less than one month and $53.7 \%$ of those traveling longer than six months. Malaria topped the list of travel concerns among travelers, with sexually transmitted infections and Ebola virus disease cited as additional concerns.

Conclusion: Long-term travelers were heavily represented in the current sample, perhaps due to current events harming shortterm tourism. Consistent with prior research, compliance with malaria prophylaxis decreased with length of travel as younger respondents trended toward poorer compliance. This survey highlights the need to accurately define "traveler" and its specific categories to better assess health risks for future travelers.

Keywords: Travel, Travel medicine, Developed countries, Patient compliance, Communicable diseases, Chemoprevention
\end{abstract}

Citation: Bias T, Allen C, Buckley A, et al. Travelers' reported preventive health behavior in Jinja, Uganda. Int J Travel Med Glob Health. 2016;4(4):107110. doi:10.21859/ijtmgh-040403.

\section{Introduction}

Growing globalization and the ease of international travel have increased the number of travelers worldwide. There are now roughly one billion international travelers each year. ${ }^{1}$ Over 68 million Americans traveled internationally in 2014, up from 61 million in $2013 .^{2}$ Half of these trips were made by people on holiday, while $11 \%$ were for business purposes. ${ }^{3}$ This increase includes travelers to low-income areas from highincome countries, bringing much of the world's population into contact with diverse cultures and different environments, confronting some with new health threats. The number of US travelers to Africa grew slightly from 2013 to 2014, signaling an increase in travel to low-income countries. ${ }^{2}$

Chronic disease in high-income countries increases the number of potential health threats facing international travelers to low-income regions. The diversity of these threats varies from infectious to non-infectious diseases in the face of industrialization and resultant climate change, alongside the 
changing demographic of travelers and the merging of cultures. Despite this, the US International Trade Administration estimates only $12 \%$ of travelers visited a healthcare provider prior to departure overseas. ${ }^{3}$ Some surveys have revealed a wide variability in seeking pre-travel health advice, reporting that $70 \%$ of travelers on trips of longer than 6 months and $49 \%$ of travelers on trips of less than a month sought pretravel medical advice. ${ }^{4}$

Considering that over half of ailments among travelers are preventable ${ }^{4}$ this study sought to determine the breadth of health advice sought prior to international travel and its effect on travelers' health behaviors, specifically in regard to visiting a low-income region.

\section{Methods}

This is a descriptive and cross-sectional study. Central-location intercept interviews were conducted with participants by one of the eight physician authors $(\mathrm{N}=127)$ at multiple sites frequented by international tourists, including cafes near the town center and local tourist offices throughout Jinja, Uganda between the dates of October 27 and October 31, 2014. Participants were accepted if they had crossed international borders to travel to Jinja, if they were age 18 or older, and if they were able to converse with their interviewer.

After verbal informed consent was given, interviewers and travelers proceeded through the 20-question semi-structured survey which involved both quantitative and qualitative questions.

Quantitative data was coded and analyzed using the Statistical Package for Social Sciences (IBM SPSS Statistics version 22.0). Qualitative information was analyzed by thematic analysis; the open-ended questions were grouped into themes until saturation was reached.

\section{Results}

A total of 127 surveys were collected. The mean age of travelers was 36.9 years $(\mathrm{SD}=15.05)$ with the mean duration of travel being 37.6 weeks (median 8 weeks; mode 2 weeks). The study population was predominantly from the United States (43.3\%), Europe (27.6\%), and the United Kingdom $(21.3 \%)$, as seen in Figure 1. Those reporting travel for less than one month and longer than six months were $40.2 \%$ and $32.3 \%$, respectively (Figure 2 ).

Over half of all participants (56.7\%) were traveling for volunteer or mission purposes, and $22.8 \%$ of all respondents were traveling for tourism. Of those traveling longer than 6 months, $73.2 \%$ were for volunteer or mission purposes and $7.3 \%$ were for tourism. This is in contrast to $41.2 \%$ of those traveling less than one month for volunteer purposes (still the dominant reason) and 39.2\% of those for tourism (Figure 3).

Of all travelers surveyed, $88 \%$ saw a healthcare provider prior to departure. Of those who stated accidents were a threat to their health while in Uganda, $58.3 \%$ and $33.3 \%$ of those had consulted a travel medicine specialist or a general practitioner, respectively, prior to departure. A much smaller fraction of this answer came from those relying solely on friends or the internet for advice.

There was a bimodal distribution of reported seatbelt use when participants were given a Likert scale of estimated percentages of time from which to choose. Half of the participants (50.4\%) reported wearing a seatbelt less than $10 \%$ of the time, and $33.9 \%$ wore one more than $90 \%$ of the time spent riding in a vehicle.

Of the participants given a prescription for malaria prophylaxis, $81.3 \%$ of participants reported current dosetaking compliance. Self-reported rates of compliance with malaria chemoprophylaxis by participants traveling less than one month versus those traveling longer than six months were $94.1 \%$ and $53.7 \%$, respectively. Figure 3 displays the comparative differences in compliance and purpose of travel between those traveling for less than one month versus those traveling for longer than six months. When broken down into categories of ages 18-30, 31-40, 41-50, 51-64, and 65 and over, compliance was $68.5 \%, 67.7 \%, 66.7 \%, 88 \%$, and $100 \%$,

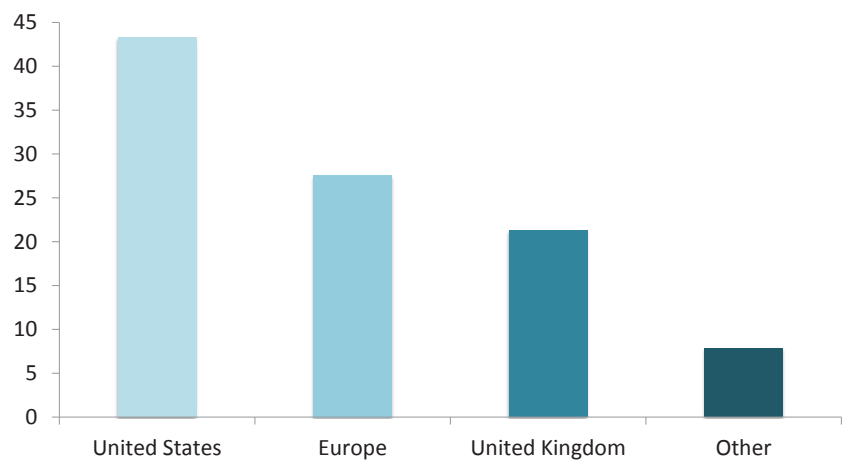

Figure 1. Participants' Nationalities (\%).

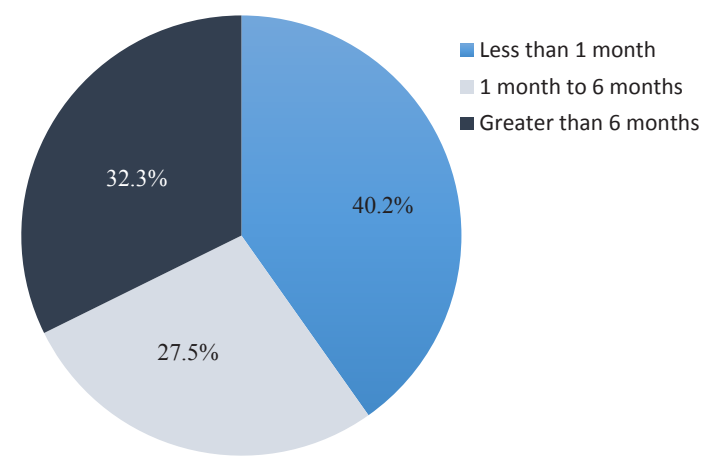

Figure 2. Participants' Duration of Travel.

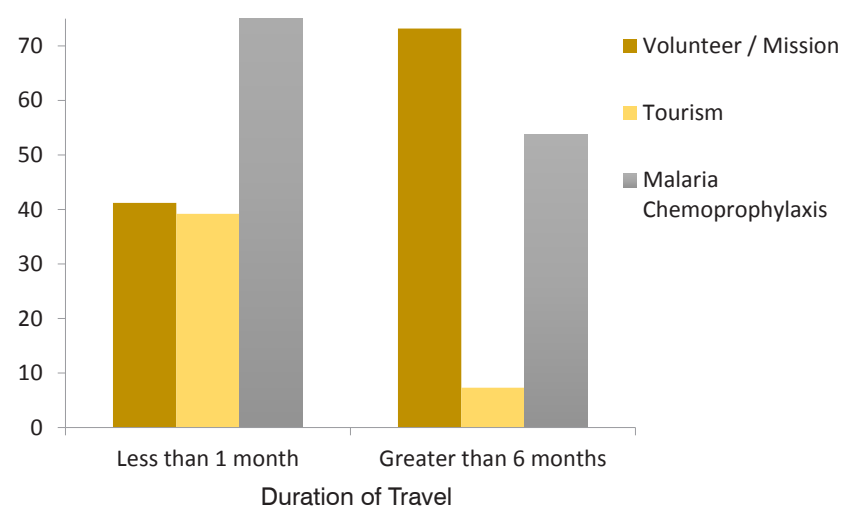

Figure 3. Purpose of Travel and Reported Malaria Chemoprophylaxis Compliance (\%). 
respectively; however, these differences are not statistically significant $(P=0.20)$. Of the 38 participants not taking malaria chemoprophylaxis, reasons cited for non-compliance included side effects (six respondents); the fact that malaria was easily treatable (seven respondents); thinking that they were immune to malaria (seven respondents), and forgetting to take the medicine (four respondents).

Malaria was reported to be the main perceived health threat to travelers in Uganda by $33.1 \%$ of respondents. The second most common response given was the "other" category (25.2\%), which included Ebola virus disease (eight respondents) and sexually transmitted infections such as HIV (seven respondents).

Actually-experienced health or safety issues during travel were reported by $24.4 \%$ of participants, $41 \%$ of which were due to diarrhea. When asked if more pre-travel medical advice was desired prior to leaving, four respondents wanted more information on Ebola, four would have liked more information on malaria, and many of the rest showed interest in anticipatory guidance regarding infectious threats such as schistosomiasis and diarrhea.

\section{Discussion}

Perhaps due to the rise in fears of terrorist attacks in northern and coastal Kenya, or secondary to increasing western media coverage of the Ebola virus disease epidemic in west Africa, the number of short-term and tourist travelers to the area appeared markedly low. This skewed the sample toward the longer-term traveler and those serving in a volunteer capacity. This sheds further light on the importance of determining the duration and purpose of travel during pre-travel consultations.

Compliance with malaria chemoprophylaxis has been shown to be $38 \%$ in Israeli travelers, ${ }^{5} 73 \%$ in US Peace Corps volunteers, ${ }^{6}$ and up to $80 \%$ in other studies of general travelers. ${ }^{7}$ These numbers vary with medication and decrease with younger age and increasing length of travel. The current survey confirmed this declining rate of chemoprophylaxis compliance inversely correlated with length of travel as well as a trend toward lower compliance among younger travelers. While deaths due to malaria among expatriates are infrequent, morbidity and costs due to malaria cases in non-indigenous travelers can be great. ${ }^{8}$ Many participants identified malaria as a major potential health threat, but the current survey revealed this to be an area where more proper pre-travel education is still desired. This is demonstrated in the reported reasons for non-compliance with chemoprophylaxis and also in the knowledge gap explicitly stated by four participants. The current study reaffirmed the necessity for strengthened guidance on compliance with malaria chemoprophylaxis, especially among longer-term travelers.

Those travelers who sought pre-travel health advice from a physician appeared more knowledgeable regarding roadtraffic accidents as a major health threat. This knowledge in addition to other obvious potential benefits, such as appropriate immunization and prescriptions for malaria chemoprophylaxis and the presumptive treatment of travelers' diarrhea, point to the importance of counseling by a health provider before travel. The United States Centers for Disease Control and Prevention (CDC) encourages a pre-travel consultation at least one month prior to an international departure, ${ }^{9}$ and this survey confirms the importance of a thorough pre-travel assessment with adequate time prior to departure.

Determining what qualifies as sufficient travel medicine leads to the question: What defines a "traveler?" Recently, there have been calls to modernize the definition of those visiting friends and relatives, or "VFR," in an effort to better assess health risks prior to international travel. This renewed focus on the purpose of travel will ideally allow the travel medicine provider to focus on true determinants of health and avoid biases sometimes associated with the ethnic background or immigrant status of the traveler. This also calls for a focus on addressing the "epidemiologic gradient" between home and destination, if present, and its associated risks. The VFR category itself was originally designed to gather economic data, rather than assess health risks. ${ }^{10}$ While all of those traveling for up to two years were examined in this study, at what point does the international traveler become a resident?

In better defining "traveler," health providers could better care for their traveling patients by focusing on the purpose and activities of the travel. Does a long-term missionary living outside his or her home country for months or years qualify? Does, then, his/her pre-travel advice change, and if it is assumed that it does, how so? Local inhabitants do not take anti-malaria prophylaxis due to increasingly understood acquired immunity and cost. Should an American missionary living in a malaria endemic area take prophylaxis, and if so, for how long? The offerings of prevention against vaccinepreventable disease ought to change as well, with a view of cumulative future exposure risk. ${ }^{11}$ Further refinement of the definition of a "traveler" as it pertains to relevant health risks would provide the travel medicine community with a standard basis on which to focus research and may uncover additional foci for the pre-travel assessment.

Missionaries and humanitarian workers show elevated rates of psychological distress during travel, ${ }^{12}$ and this group was well represented in the current study population. Further study into the mental health needs of travelers, especially during and after humanitarian crises or even after shortterm mission trips, would serve as an interesting next step in serving all needs in comprehensive travel medicine care.

The current study is simply a snapshot from one city in Uganda in 2014. The findings require the care of interpretation that all self-reported data and the aforementioned temporal context demand. Future studies of larger populations of international travelers in a more randomized fashion would afford increased internal and external validity regarding differences in health needs and attitudes by age group, length of trip, and purpose for travel. Length of travel has been shown to be associated with different health risks, such as worsening food safety practices and the aforementioned decreasing adherence to malaria prophylaxis, as trip duration lengthens. ${ }^{13}$ In accepting the definition of "traveler" as one traveling across an international border and for less than two years, valuable lessons to be learned from longer-term travelers and those traveling from rural areas to more urban centers may have been missed.

\section{Conclusion}

In a time of increasing international travel, this survey of 
travelers in Jinja reveals that there is still room for improvement in identifying and mitigating health risks among travelers to low-income regions and in refining the definition of a traveler.

\section{Authors' Contributions}

$\mathrm{TB}$ is the corresponding author and conducted the quantitative data analysis. TL and $\mathrm{AB}$ conducted qualitative data analysis. TL created all figures. All authors contributed equally to data collection, draft preparation, and revisions.

\section{Conflict of Interest Disclosures}

The authors declare that they have no competing interests.

\section{Ethical Approval}

Institutional Review Board approval was not required for this study.

\section{Funding/Support}

This research received no specific grant from any funding agency in the public, commercial, or not-for-profit sectors.

\section{References}

1. Tourism Highlights: 2014 Edition. 1st ed. UN World Tourism Organization; 2014. http://dtxtq4w60xqpw.cloudfront.net/sites/ all/files/pdf/unwto_highlights14_en.pdf. Accessed March 21, 2015.

2. Monthly Departures to International Destinations. Travel.trade.gov website. http://travel.trade.gov/view/m-2014-O-001/index.html. Accessed February 21, 2015. Published 2015.

3. U.S. Travel To International Destinations Increased Two Percent in 2013. US International Trade Administration; 2014.

4. Chen L, Wilson M, Davis $X$, et al. Illness in long-term travelers visiting GeoSentinel clinics. Emerg Infect Dis. 2009;15(11):17731782. doi:10.3201/eid1511.090945.

5. Goldstein I, Grefat R, Ephros M, Rishpon S. Intent-to-adhere and adherence to malaria prevention recommendations in two travel clinics. Journal of Travel Medicine. 2015;22(2):130-132. doi:10.1111/jtm.12156.

6. Landman KZ, Tan KR, Arguin PM, Centers for Disease Control and Prevention (CDC). Knowledge, attitudes, and practices regarding antimalarial chemoprophylaxis in U.S. Peace Corps Volunteers Africa, 2013. MMWR Morb Mortal Wkly Rep. 2014;63(23):516-7.

7. Hill D. Health problems in a large cohort of americans traveling to developing countries. J Travel Med. 2000;7(5):259-266. doi:10.2310/7060.2000.00075.

8. Westercamp N, Arguin P. Malaria chemoprophylaxis: a proven public health intervention for international travelers. Travel Med
Research Highlights

\section{What Is Already Known?}

- Rates of international travel, including to low income areas, are increasing.

- Few travelers visit a health provider for medical advice prior to departure.

- Half of medical ailments acquired during travel are preventable.

- Compliance with malaria chemoprophylaxis varies with duration of travel and age of traveler.

\section{What This Study Adds?}

- Travelers who sought pre-travel medical advice appeared more knowledgeable about the threat such as road traffic accidents.

- Our sample showed better adherence to malaria chemoprophylaxis amongst these longer-term travelers and trended towards better adherence amongst older travelers.

- A large portion of our sample were traveling for longer than six months, pointing to the need for better defined terms regarding the "traveler" and categories such as those Visiting Friends and Relatives, or "VFR," for future Travel Medicine research.

Infec Dis. 2015;13(1):8-9. doi:10.1016/j.tmaid.2014.12.006.

9. Centers for Disease Control and Prevention. Travelers' health: see a doctor before you travel. Atlanta, GA: US Department of Health and Human Services, CDC; 2013. http://www.cdc.gov/travel/ page/see-doctor. Accessed March 1, 2015.

10. Barnett E, MacPherson D, Stauffer W, et al. The visiting friends or relatives traveler in the 21st century: time for a new definition. J Travel Med. 2010;17(3):163-170. doi:10.1111/j.17088305.2010.00411.x.

11. Leder K, Chen L, Wilson M. Aggregate travel vs. single trip assessment: arguments for cumulative risk analysis. Vaccine. 2012;30(15):2600-2604. doi:10.1016/j.vaccine.2011.12.133.

12. Leutscher P, Bagley S. Health-related challenges in United States Peace Corps Volunteers serving for two years in Madagascar. J Travel Med. 2003;10(5):263-267. doi:10.2310/7060.2003.2690.

13. Hamer D, Ruffing R, Callahan M, Lyons S, Abdullah A. Knowledge and use of measures to reduce health risks by corporate expatriate employees in Western Ghana. J Travel Med. 2008;15(4):237-242. doi:10.1111/j.1708-8305.2008.00214.x. 